\title{
Evergreen Library
}

\section{Penetrating into Classroom Teaching:}

\section{Applying and Expanding -}

\section{Take Tianzhu No.1 High School \\ in Northwest China as a Sample}

Zhou Wenjie

Evergreen Rural Library Service Center

China

\begin{abstract}
This paper provides a study of the school library programs sponsored by the Evergreen Education Foundation (EEF) and identifies the vital role of school libraries in improving students' information quality. Based on analyzes Strategies for building literacy skills in the library of Tianzhu No.1 High School, the study confirmed the program developed reading and literacy skills among students. As EEF programs continue to expand into other locations in China, it is the authors' hope that this study may provide useful information and analysis based upon which decisions about future programs can be made. It is also their hope that this study provides impetus for more studies on the rural library programs in other areas of China or programs in other underdeveloped regions of the world.
\end{abstract}

China, literacy skills, rural libraries

\section{Evergreen Education Foundation and Its School Library Projects in Tianzhu N0.1 high school}

\section{Evergreen Education Foundation (EEF)}

EEF, a U.S. based non-profit organization, was founded in 2001 to help combat poverty and illiteracy in rural areas of China by providing free access to information resources. Upon its inception, EEF set as its mission "to improve education opportunities for children and young adults in rural China by providing books, computers, relevant equipment and supplies, workshops, and seminars to schools and libraries"i. The long-term objective of EEF is to improve the quality of life in rural communities via school library projects. For the past seven years, the EEF has sponsored 38 school and public libraries in six provinces or regions, including the most backward provinces such as Qinghai, Gansu, Shaanxi, Guizhou and Yunnan. It supports nearly 200 scholarship students each year. ${ }^{\text {ii }}$ Subsequently these libraries serve a combined student population of nearly 20,000 and a combined community population of well over a million.

\section{China Evergreen Rural Library Service Stations (CERLS)}


CERLS was established in 2002 as a sub entity under the Education Bureau of Qinghai Province as EEF's Chinese partner. Through CERLS, partnerships between EEF and libraries are signed, funds are distributed and managed, and regional liaisons are appointed. Currently CERLS is headquartered in Beijing. Its regional liaisons in Qinghai, Gansu, Shaanxi, Yunnan, Guizhou, and Jiangsu provinces are responsible for the communication among CERLS libraries in their regions as well as the coordination of cross-regional activities or programs. In 2004, CERLS received the Bill \& Melinda Gates Foundation Access to Learning Award for its innovative programs and pioneering works. The benevolent award from the Gates Foundation has provided additional funding for CERLS to sustain its initiatives and programs.

\section{School-Library-Centered Community Information Resource Sharing Model}

The design of the school-library-centered model recognizes the power of influence derived from the following communication pattern:

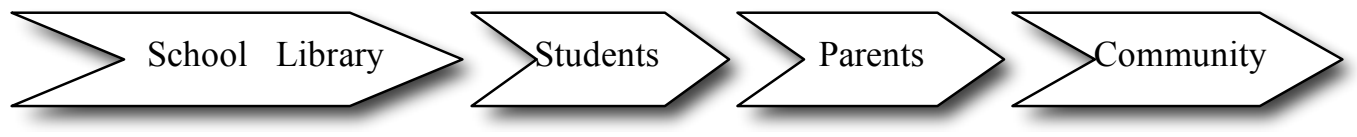

A school library, if adequately funded and staffed, promotes reading and learning activities of students who subsequently would bring home knowledge and information searching skills acquired from school and thus exert immediate influence on the learning behaviors of their parents, as a large percent of the parents did not receive standard education due to poverty and other historical reasons. Skills of using library tools and resources as well as the use of computer, Internet, and multi-media, nowadays are required as part of the teaching curriculum. These skills and the knowledge acquired with the aid of school librarians enable a student to be an immediate trainer or tutor of their under-educated parents and family members. The free information services provided by a school library encourage all who eager to empower themselves through reading and learning. These interactions between a school librarian and students, students and parents, and parents and a school library stimulate a healthy learning environment in the building of a learning community.

Recognizing the educational role of school libraries which serve as the most immediate gateway in connecting rural communities to a world of information and information technology, EEF decided to use them to " place information technology in the hand of those who need it most" iii and developed a school-library-centered community information resource sharing model that can be implemented by the following strategies: (1) building a library network by establishing satellite libraries and book stations around a revitalized high school library; (2) connecting these libraries through library management software and the Internet to extend information access to indigenous peoples; and (3) promoting library services to communities through school students and their parents to maximize the results of outreach programs, such as extending free library borrowing privilege to parents, conducting cultural lectures as well as workshops on computers and the Internet, and providing reference services on farming technology and other skills.

To match up with the model and projects, EEF has contributed to each library network the following necessary facilities and equipments: library automation software, and a computer server to host the software at the high school library center; computers to search online catalog, a digital camera to make photos for library borrowing cards, a laser printer, a barcode scanner, books, and facilities to connect each other through the Internet at each library and book station in the network. EEF has also helped finance online reading rooms in 
some libraries.

The information resource-sharing model can be illustrated by the following chart:

Chart 1 -- A School-Library-Centered Community Information Resource Sharing Model

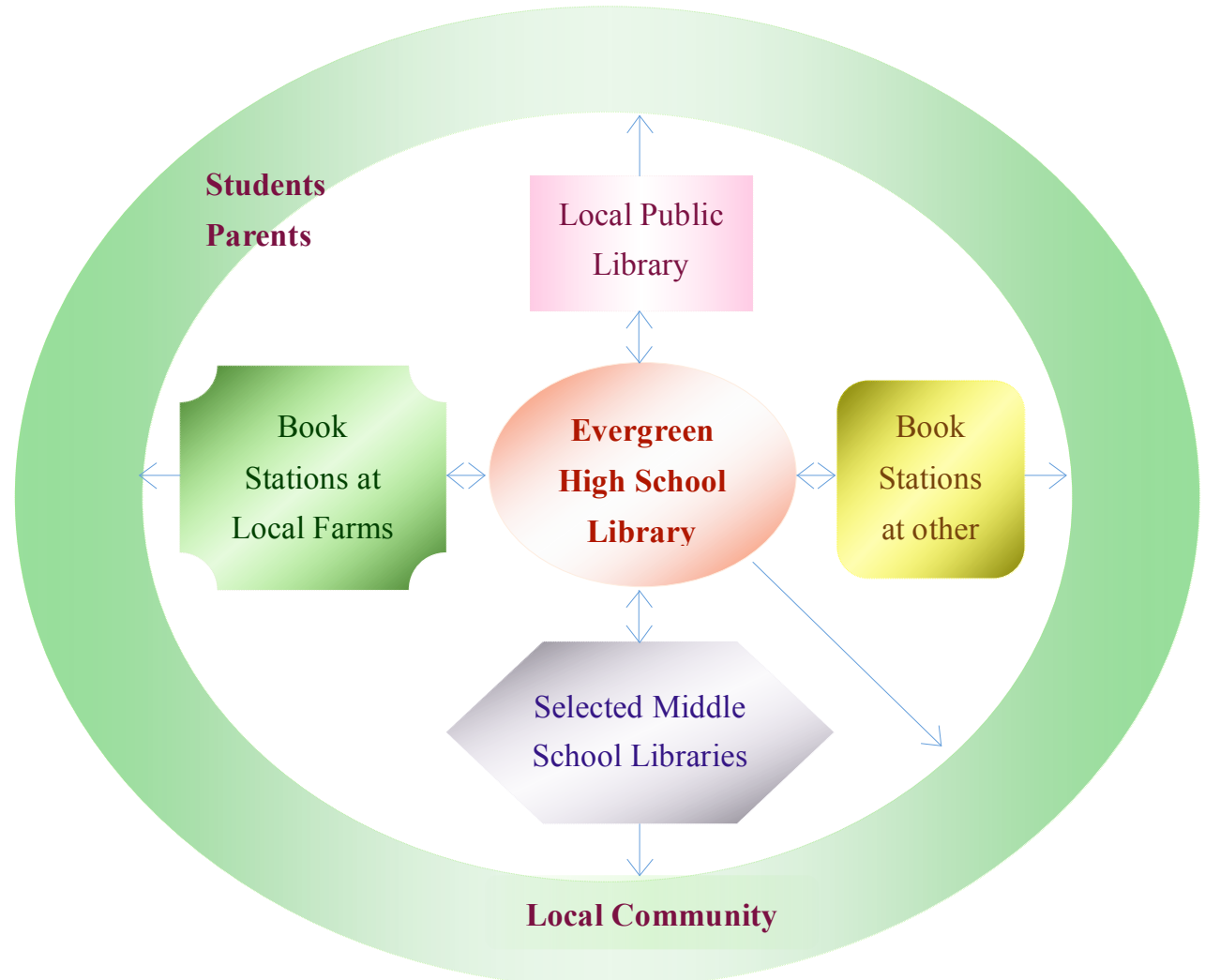

\section{The program Implementation in Tianzhu No.1high school}

Tianzhu County is listed among the 43 poorest counties in Gansu province. ${ }^{\text {iv }}$ This with a population of 230,000 and a slow economy limited mainly to agricultural and livestock industries, is also an autonomous prefecture of 13 ethnic groups with Han Chinese and Tibetan as the two largest ethnic groups. Other ethnic minorities in Tianzhu include Muslim Hui, Mongolian, etc.

There are around 4,600 students and 208 teachers in Tianzhu No.1 High School it. Since 2001, Evergreen Education Foundation has carried out a program to help the school build a modern library realizing computerized management and building online reading systems. Today, Tianzhu No. 1 High School Library boasts over 41,000 books and subscribes to over 140 journals and newspapers. And the library of Tianzhu No. 1 high school has online reading rooms equipped with over 60 computers. The library provides free access to a Chinese e-database (sponsored by a vendor). Besides, the Foundation also subsidizes students from poor families. Meanwhile the school librarians try to improve efficiency of the library in order to elaborate the beneficial result of the program on which the present paper is based as follows. 


\section{Strategies for building literacy skills in the library of Tianzhu No.1 High School.}

\section{Develop a school based on curricular twice a week}

How to improve students' ability of reading and make full use of the library for students' study is a key problem to the teachers and librarians in Tianzhu No.1 High School. Since 2003, after a new modern library was built in the school, all students have had a new curriculum named "reading class" twice a week. The class is quite different from traditional ones. Students have their reading lessons in the library instead of in the classrooms. And in these classes students not only read but also have formal lessons in the library. The school librarians become real teachers; it's the first time for them to organize classes just as mathematics or physics teachers do. In Tianzhu County, there are 15 middle schools and more than 200 other forms of schools, Tianzhu No.1 High School is the only one to open reading lessons in the library for students.

Reading lessons contain 5 contents to train the students' information quality as follows:

- The skill of library classification. In these lessons librarians show the students some books that haven't been classified. Each student has a chance to learn how to assign a right number for the book and how to put the book in the right place. This type of lessons takes 6-8 hours.

- How to make books catalogged. Librarians teach students how to catalog books into a computer program. As an examination item, students will be given a task to catalog books into a computer in a fixed time. Before these lessons the computer teacher has taught students some necessary skills such as writing input. These lessons take 6-8 hours.

- How to find a book by using computer program in the library. In this subject, students have a chance to search books from computer by a different way, such as how to search a book by its author or key word and so on. These lessons take 6-8 hours.

- How to explore useful information by using the Internet. The Internet becomes the most important and powerful information source for students. Even in the underdeveloped area like Tianzhu, students must learn how to use the Internet well. In reading classes, librarians help students get into web and search what they interested in. Before the modern library was built in 2003 , nearly $80 \%$ of the students had never touched the Internet. But now, all students can use the Internet very well. These lessons need 10 class hours.

- Volunteers, just as a reader's assistant, serve all students. All these volunteers are subsidized by Evergreen Education Foundation. There are more than 30 volunteers working in the school library. All these students come from poor families. Librarians give the volunteers special lessons to make them familiar with the management of library. After class, the volunteers not only help librarians to manage the library but also help other students to find what they want. In fact, volunteers become a useful assistant for the students.

- School librarians are supported by senior staff of the school holding reading incentive programs such as reading contest each team. In Tianzhu No.1 High School, each team 
has several contests. Some of them are reading contests. Each time the reading contest has different titles, such as to search for the history of Xiliang country (this country existed in the area near Tianzhu 1300 years ago) by using resource from the library. The winner in these contests will get reward and be accepted as a volunteer for the library. Through these programs, students come to show more and more interest in reading and other affairs of the library.

\section{The program develops reading and literacy skills among students}

1. Students can explore useful information (include books, papers and digital resources) efficiently. By building the modern library and opening the reading lessons, all students can share resources from library equally. Restricted by poor families, many students may have no chance to get so many information resources. But the library and reading lessons change this situation. Now every student has skills to search books, papers and other resources from computer and get into web to find what they are interested in. It is inconceivable in other schools in Tianzhu. The higher information accomplishment becomes a special feature for those students' study in Tianzhu No.1 high school.

2. Students can keep pace with changes of the world. Tianzhu county is located far- away from city, the information is so unenlightened that many people living in this area are secluded from the world. But now, the library and the reading lessons has opened a window to all the students and their parents. Through the bridge of the library, many students for the first time know that things happened in the modern world. An investigation held by Tianzhu No. 1 high school shows that nearly $80 \%$ of the students first time got into web by the school library.

3. Students have learnt how to understand the diversity of culture. In the Tibetan autonomous region about 50\% people living in Tianzhu are Tibetans. So the program correlates between library services and the cultural life of various ethnic groups. By owning more information, most of the students come to understand cultures and life styles of other ethnics and countries.

4. Students have learnt suitable ways to gain the information resources and follow net standard. Reading lessons not only teach students how to get more and more useful information from library and Internet, but also teach them relevant rules. Through these lessons students gain the skill to explore the information and also form the virtues of information.

\section{Results of the program}

The program is still ongoing, but there are many positive results occurring: 


\section{Broadened the field of vision of students}

As we discussed above, the program gives a chance to students to open their eyes to the outside world. They come to understand the different cultures and ideas. Also most of students come to a new view of the world. Especially for Tibetan students, they live in the area far away from city and have no other ways to understand what happens in today's world. On the other hand, the program changes many students' ideas about other ethnic people and makes more and more students realize that they live in an area of cultural diversity. The program also leads students to know the advanced technology and some other fields.

\section{Eliminate the digital gap between students}

Developing education fair is for all students, especially for those students from poor families. If there were not this program, many students in Tianzhu No.1 High School would never share the Internet resources at all and they would also have no chance to understand what happens in the world. All in all they will have no chance to change their life and mind.

\section{Have a positive effect on students' school grades}

In a survey held by Tianzhu No.1 High School, the program has made a positive effect on students. The result shows that since the reading lessons' beginning, students have become more interest in Chinese, History and many other subjects.

\footnotetext{
${ }^{\mathrm{i}}$ Evergreen Education Foundation home page:

http://www.evergreeneducation.org/EvergreenNew/missionstate.htm,
}

${ }^{2}$ Evergreen 2007 Newsletter

${ }^{3}$ Geoffrey Liu, "Evergreen Bringing Information Resources to Rural China: Bill \& Melinda Gates Foundation Access to Learning Award Recipient 2004.” Washington, D.C. Council on Library and Information Resources, 2005.

iv The poverty line set by Chinese government three years ago specifically identify any individual with an annual income less than 882 Yuan $(\$ 106)$ as poor. The Chinese standard is lower than that of World Bank which set a poverty threshold of an individual who makes less than $\$ 1$ a day. The population we sampled for this study shows that average individual income of Tianzhu (still listed as below poverty line) is all above the poverty line set by Chinese government and World Bank.

\section{Statement of Originality}

This statement certifies that the paper above is based upon original research undertaken by the author and that the paper was conceived and written by the author(s) alone and has not been published elsewhere. 